Publicação organizada pelo Programa de

Mestrado Profissional Stricto Sensu em

Engenharia Civil da Universidade São Judas

Volume 02 - Edição 01

Janeiro - Dezembro de 2019

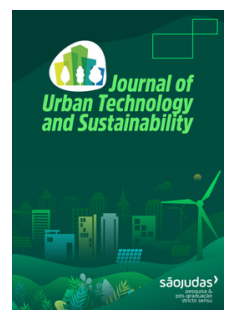

\title{
Percepção, uso e afetividade de frequentadores de praças públicas na cidade de São Paulo, Brasil
}

Kelly C. Oliveiraa, Ana Paula B. Nascimentoa,, Heidy R. Ramos ${ }^{a, b}$, Cláudia T. Kniess ${ }^{c}$, Simone Aquinoa

aprograma de pós-graduação em Administração, Gestão Ambiental e Sustentabilidade, Universidade Nove de Julho - UNINOVE, São Paulo, Brasil.

${ }^{b}$ Programa de pós-graduação em Cidades Inteligentes e Sustentáveis, Universidade Nove de Julho - UNINOVE, São Paulo, Brasil.

${ }^{c}$ Programa de Pós-graduação em Gestão e Desenvolvimento Regional, Universidade de Taubaté - UNITAU.

\section{Informações}

Recebido 27 Abril 2019

Manuscrito revisado recebido

O7 Junho 2019

Aceito 13 Junho 2019

Palavras-chave

Espaços públicos

Áreas verdes

Urbanização

Planejamento Urbano

\section{Resumo}

O presente trabalho analisou a percepção de frequentadores sobre cinco praças da cidade de São Paulo e o uso destes espaços. Foram realizadas entrevistas exploratórias com frequentadores. Os resultados indicam que áreas verdes, segurança, localização, lazer, atividade física estão entre os itens que contribuem para sentimentos positivos, assim como a decisão de usar estes espaços. Infraestrutura como, presença de bancos, lixeiras, banheiros e outros elementos que prolonguem a estadia do visitante na praça e aumente seu conforto ao visitar o espaço é percebido, utilizado e considerado muito importante pelos frequentadores. Não há padrão no planejamento das estruturas e equipamentos em diferentes praças, uma vez que a gestão é descentralizada. As percepções das praças pelos frequentadores podem auxiliar na criação de projetos bases, com elementos semelhantes, que atendam a essas expectativas em comum. Dessa forma, torna-se relevante ser considerado pelos gestores públicos, pontos fracos e fortes percebidos por frequentadores.

\section{Environmental perception, use and affectivity of public square user in the city of São Paulo, Brazil}

\section{Article info}

Received 27 April 2019

Received in revised form 07 June 2019

Accepted 13 June 2019

\section{Keywords}

Public spaces

Green areas

Urbanization

Urban Planning

\begin{abstract}
The present study analyzed the perception of regulars about five squares of the city of São Paulo and the use of these spaces. Exploratory interviews were conducted with attendees. The results indicate that green areas, safety, location, leisure, physical activity are among the items that contribute to positive feelings, as well as the decision to use these spaces. Infrastructure such as the presence of benches, bins, bathrooms and other elements that prolong the stay of the visitor in the square and increase their comfort when visiting the space is perceived, used and considered very important by the regulars. There is no standard in planning structures and equipment in different squares, since management is decentralized. The perceptions of the squares by the regulars can help in the creation of base projects, with similar elements, that meet these common expectations. In this way, it becomes relevant to be considered by public managers, weak and strong points perceived by regulars.
\end{abstract}

\section{Percepción, uso y afectividad de visitantes de plazas públicas en la ciudad de São Paulo, Brasil}

\section{Información}

Recibido 27 Abril 2019

Manuscrito revisado recibido

07 Junio 2019

Aceptado 13 Junio 2019

\section{Palabras clave}

Espacios públicos

Áreas verdes

Urbanización

Urbanismo

\section{Resumen}

El presente trabajo analizó la percepción de los visitantes sobre cinco plazas de la ciudad de São Paulo y el uso de estos espacios. Fueron realizadas entrevistas exploratorias con los visitantes. Los resultados indican que las áreas verdes, seguridad, ubicación, ocio y actividad física se encuentran entre los aspectos que contribuyen para sentimientos positivos, así como la decisión de utilizar estos espacios. La infraestructura como: presencia de bancos, basureros, baños y otros elementos que prolongan la estadía del visitante en la plaza y aumenta su comodidad al visitar el espacio es percibida, utilizada y considerada muy importante por los visitantes. No existe un modelo en la planificación de las estructuras y equipos en diferentes plazas, ya que la gestión está descentralizada. Las percepciones de las plazas por parte de los visitantes pueden ayudar en la creación de proyectos base, con elementos similares, que cumplan con estas expectativas comunes. Por ello, es relevante para ser considerado por los gestores públicos, las debilidades y fortalezas percibidas por los visitantes.

\footnotetext{
* Autor correspondente em: Programa de pós-graduação em Administração, Gestão Ambiental e Sustentabilidade, UNINOVE, São Paulo, Brasil. E-mail: apbnasci@yahoo.com.br (Ana Paula B. Nascimento)
} https://doi.org/10.47842/juts.v2i1.11 ISSN: 2675-780X 


\section{Introdução}

O desafio no planejamento e manutenção de espaços verdes públicos urbanos no mundo difere entre países em desenvolvimento e países desenvolvidos (SHACKLETON; BLAIR, 2013). Estudos realizados na África e China mostram que diferentes perfis sociais populacionais percebem e utilizam os espaços verdes urbanos de maneiras divergentes (JIM; CHEN, 2010; LO; JIM, 2010). Dentre os espaços públicos, destacam-se locais como parques, praças e quintais (SUSHINSKY et al., 2013). Estes espaços são relevantes por proporcionarem interações entre a população humana e recursos vegetais, reduzidos com a crescente urbanização.

No Brasil, as praças são espaços públicos encontrados na maioria dos municípios, desempenhando papel na melhoria da qualidade de vida ambiental e social (BARROS; VIRGILIO, 2003; BENCHIMOL et al., 2017). Em grandes centros urbanos demonstram ser importantes nichos de conservação (DE ANGELIS et al., 2004; DORIGO; LAMANO-FERREIRA, 2016), aumentando os índices de áreas verdes (IAV) e minimizando impactos do crescimento urbano desordenado. De acordo com Costa e Colesanti (2011) e Tuan (2012) pesquisas sobre percepção ambiental contribuem para estudos sobre áreas verdes.

A maioria dos trabalhos refere-se às praças como espaço público aberto, com vegetação e destinadas ao lazer e convívio social (BARROS; VIRGILIO, 2003; LOBODA; DE ANGELIS, 2005; HARDER et al., 2006; SOUZA et al., 2011; DORIGO; LAMANO-FERREIRA, 2016). Entretanto, não existe um conceito único que englobe todos os tipos de praças, sendo alguns espaços nomeados praças sem possuir vegetação. Este é um grande problema para uma megacidade como São Paulo, a qual apresenta uma grande desigualdade em sua cobertura vegetal.

A percepção da população sobre o ambiente e mais especificamente sobre as áreas verdes é uma ferramenta indispensável para a melhoria da qualidade do ambiente urbano e depende de diferentes fatores. Pode-se destacar o valor atribuído a esses espaços pela população e como esta percebe as condições ambientais e os utilizam (COSTA; COLESANTI, 2011). Santos et al. (2018) mostram que munícipes que reconhecem a importância da arborização urbana também se dispõem em contribuir financeiramente em prol de melhorias no planejamento.

A partir do exposto, a questão de pesquisa do presente estudo foi: Quais as percepções, sentimentos e uso de frequentadores sobre praças públicas da cidade de São Paulo? O conhecimento de como os frequentadores percebem, se relacionam e utilizam as praças, contribuem com soluções para os desafios dos gestores, além de dar respostas às expectativas da população (DORIGO; LAMANO-FERREIRA, 2016).

\section{Materiais e métodos}

\subsection{Descrição da área de estudo}

Foi realizado um estudo qualitativo de natureza exploratória, com aplicação de questionário para 15 frequentadores ( $n=3 /$ praça) de 5 praças da cidade de São Paulo, com extensão entre 13.000 e 18.000 m2. Os espaços públicos selecionados foram: Praça Floriano Peixoto (zona Sul), Praça Franklin Roosevelt (Centro), Praça Benedito Calixto (zona Oeste), Praça Sílvio Romero (zona Leste) e Praça Novo Mundo (zona Norte). Cabe destacar que cada um destes espaços é administrado por uma Prefeitura Regional, sendo a gestão descentralizada (BENCHIMOL et al., 2017). Esta informação torna mais relevante conhecer a percepção de frequentadores sobre diferentes modelos de planejamento em espaços públicos.

\subsection{Coleta e análise dos dados}

Duarte (2004) apontou que a realização de entrevistas é o método mais eficaz quando se almeja conhecer em maior profundidade como um grupo de indivíduos percebe e dá significado à sua realidade. Foi elaborado um roteiro semiestruturado, com perguntas fechadas e abertas, construído com base nas diretrizes contidas no guia Guidelines for field studies in environmental perception (WHITE, 1977). As questões abertas foram utilizadas para 


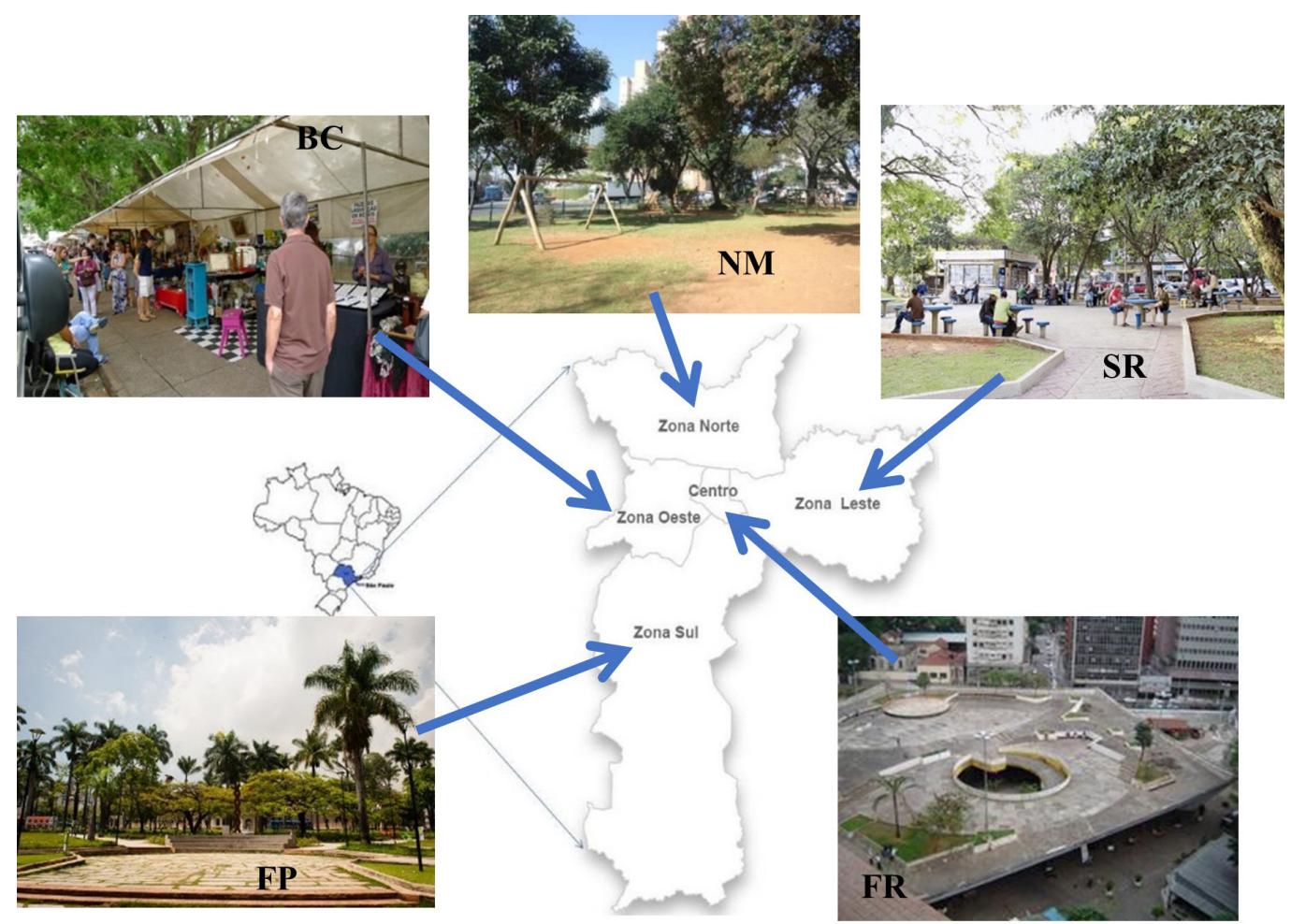

Fig. 1. Praças estudadas, localizadas em diferentes regiões da cidade de São Paulo. Floriano Peixoto (FP), Franklin Roosevelt (FR), Benedito Calixto (BC), Sílvio Romero (SR) e Novo Mundo (NM).

a categorização e julgamento, e as perguntas fechadas para as características individuais, com o registro das respostas gravadas e posterior transcrição. A realização das entrevistas se deu em dias da semana variados, nos períodos da manhã e tarde.

O perfil do respondente seguiu os critérios adotados e estabelecidos pelo Instituto Brasileiro de Geografia e Estatítica (IBGE), em que determina o conceito de frequentador: a) ser frequentador da praça há pelo menos 3 anos; b) visitar a praça ao menos 1 vez por semana ; c) pertencer a uma das 3 faixas etárias estipuladas (Faixa 1 - 15 a 29 anos, Faixa 2 - 30 a 59 anos e Faixa 3 - acima de 60 anos).

Segundo White (1977) o processo de descrição é a melhor técnica para se registrar elementos conscientes e inconscientes da percepção ambiental de um indivíduo. As perguntas abertas foram formuladas de modo a estimular o respondente a descrever as atividades que costuma praticar na praça, sua motivação para a visita, sugestões de melhorias futuras desejadas e como se sentiria com a extinção da praça (Figura 2).

As perguntas fechadas incluídas são referentes ao gênero, idade, nível de escolaridade, renda média familiar, ocupação, bairro de residência, quantidade de vezes que frequenta a praça, tipo de residência casa ou apartamento, número de filhos e animais de estimação.

\section{Resultados e discussão}

Os resultados foram divididos em duas partes: perfil dos frequentadores e percepção sobre a praça.

\subsection{Perfis dos frequentadores}

O Quadro 1 apresenta o detalhamento do perfil de cada entrevistado (E) por praça, permitindo a verificação destes perfis. Os respondentes têm características bem heterogêneas, independente das praças.

A maioria dos frequentadores mora no mesmo bairro em que a praça está localizada ou em bairros vizinhos. Apenas dois entrevistados residiam em regiões mais distantes das praças. Sete entrevistados residiam em casas e oito em apartamentos. Dentre 


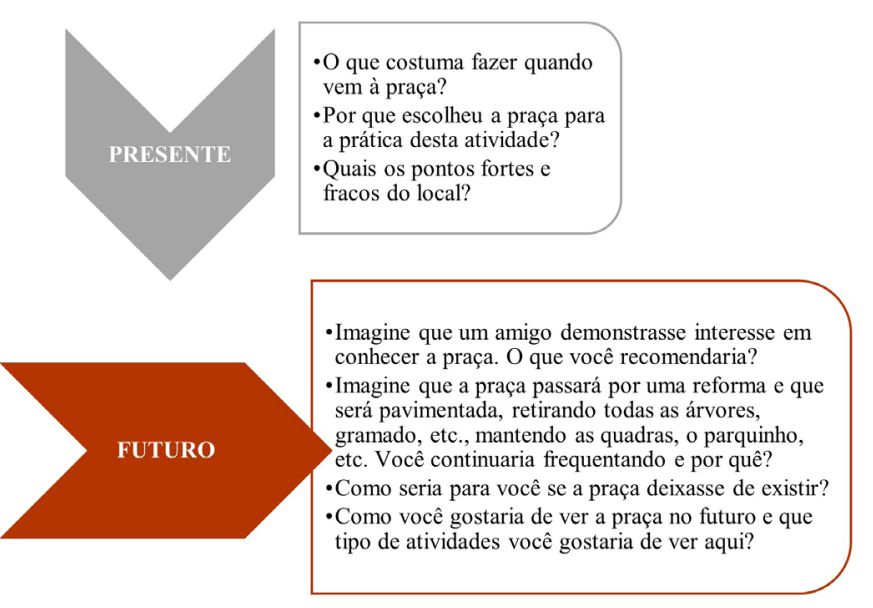

Fig. 2. Perguntas abertas aos respondentes sobre atividades e percepções de cinco praças públicas.

os que possuíam filhos pequenos, a maioria revelou levar as crianças para brincar na praça, assim como os cães, especialmente nas praças Franklin Roosevelt e Benedito Calixto, onde há espaço próprio para animais.

Este equilíbrio de características no perfil dos entrevistados sugere que a praça é um local que atrai perfis socioeconômicos variados (idade, escolaridade e renda) da população paulistana. Isto rebate a ideia de que seria frequentada apenas por pessoas que não possuem condições para consumir ou frequentar espaços de lazer privados (THOMPSON, 2012). Também se constatou frequentadores com níveis de escolaridade variados, bem como a renda média familiar. Frequentadores da Praça Benedito Calixto e a Franklin Roosevelt apresentaram renda elevada e das praças Floriano Peixoto e Novo Mundo mais baixa.

\subsection{Percepção dos frequentadores sobre as praças}

A análise qualitativa das respostas, permitiu construir nove categorias relacionadas a percepção e uso das praças pelos frequentadores: 1. Estrutura e equipamentos; 2. Área verde; 3. Segurança; 4. Localização, espaço e acesso; 5. Lazer e descanso; 6. Atividade física e esporte; 7. Compras e alimentação; 8. Socialização e cultura; e 9. Topofilia.

\subsubsection{Estrutura e equipamentos}

As observações frente aos aspectos estruturais das praças estão apresentadas no Quadro 2, que foram classificados em pontos fortes e fracos.

O equilíbrio entre pontos fracos e fortes foram observados na Praça Benedito Calixto, em oposição nas demais praças, onde foram observados mais pontos fracos, em relação à estrutura desejada pelos frequentadores. A falta de manutenção de equipamentos e espaço apropriados para a prática de atividade física foi observada por $40 \%$ dos entrevistados. A quadra e os aparelhos de exercícios para idosos foi o ponto forte observado apenas na Praça Benedito Calixto, como reportado pelo respondente E11, como itens almejados pela população. Os bancos são elementos que contribuiriam para a permanência dos visitantes na praça por mais tempo. Entretanto, 26\% dos entrevistados, especialmente nas praças Floriano Peixoto e Benedito Calixto, consideraram insuficientes.

Outro item almejado nas praças são playgrounds ou áreas para crianças brincarem, conforme relatos (E4, E7 e E15). Esta percepção de 20\% dos respondentes enfatiza a ideia de praça como local de lazer para uma faixa específica da população, que segundo Thompson (2002 e 2008) é um dos principais públicos das praças. A Praça Benedito Calixto apresentou o parquinho como ponto forte observado (E11). Apenas 20\% dos entrevistados (E2, E5 e E11) apontaram outros itens como pontos fracos nas praças Franklin Roosevelt, Floriano Peixoto e Benedito Calixto, como a falta de um "cachorródromo", banheiros e bebedouros, respectivamente.

Pontos fracos observados sobre o estado de conservação apontam as praças Sílvio Romero, Benedito Calixto e Novo Mundo, por $26 \%$ dos respondentes (E5, E12, E14 e E15), referente à limpeza e manutenção precárias. Por outro lado, a percepção de uma das entrevistadas (E14) sugere que esta manutenção não é de responsabilidade única dos gestores da praça, mas também dos frequentadores e associações, corroborando a opinião do entrevistado E10 como uma responsabilidade compartilhada, a despeito da falta de recurso da associação da Praça Benedito Calixto, apontado pelo respondente E12. 
Quadro 1. Informações sobre os entrevistados de cinco praças públicas estudadas na cidade de São Paulo, SP.

\begin{tabular}{|c|c|c|c|}
\hline Praça Franklin Roosevelt & E 1 & E 2 & E 3 \\
\hline Praça Franklin Roosevelt & E 1 & E 2 & E 3 \\
\hline Sexo / Idade: & Homem / 17 anos & Mulher / 49 anos & Homem / 74 anos \\
\hline Bairro: & Consolação & Consolação & Consolação \\
\hline Tipo de moradia: & Apartamento & Apartamento & Apartamento \\
\hline Escolaridade: & Médio cursando & Superior & Superior \\
\hline Filhos: & Não possui & Não possui & 1 filha de 1 ano \\
\hline Animais de estimação: & Não possui & 2 cachorros & 1 cachorro \\
\hline Ocupação: & Estuda & Trabalha & Aposentado \\
\hline Renda média familiar: & RS 5.000 & $R \$ 6.000$ & RS 3.000 \\
\hline Frequência na praça & Diária & Diária & Diária \\
\hline Tempo que frequenta & 8 anos & 15 anos & 30 anos \\
\hline Atividade praticada: & Skate com amigos & Conversar com amigas & Passear com a filha \\
\hline Praça Floriano Peixoto & E 4 & E 5 & E 6 \\
\hline Sexo / Idade: & Mulher/ 17 anos & Homem/ 44 anos & Homem / 65 anos \\
\hline Bairro: & Taboão da Serra & Santo Amaro & Jd. São Luiz \\
\hline Tipo de moradia: & Casa & Casa & Casa \\
\hline Escolaridade: & Ensino fundamental & Ensino fundamental & Primário \\
\hline Filhos: & 1 filha de 1 ano & 1 filho adulto & 2 filhos adultos \\
\hline Animais de estimação: & Não possui & 1 tartaruga & 1 cachorro / 1 gato \\
\hline Ocupação: & Dona de casa & Trabalha & Aposentado \\
\hline Renda média familiar: & $\mathrm{R} \$ 1.300,00$ & R\$ 3.000,00 & R\$ 800,00 \\
\hline Frequência na praça & 1 vez por semana & Diariamente & 1 vez por semana \\
\hline Tempo que frequenta: & Mais de três anos & 30 anos & 40 anos \\
\hline Atividade praticada: & Brincar com a filha & Conversar com amigos & Assistir apresentação musical \\
\hline Praça Silvio Romero & E 7 & E 8 & E 9 \\
\hline Sexo / Idade: & Homem/ 23 anos & Homem/ 35 anos & Homem/ 74 anos \\
\hline Bairro: & Penha & Jd. América & Tatuapé \\
\hline Tipo de moradia: & Casa & Apartamento & Casa \\
\hline Escolaridade: & Superior cursando & Superior completo & Ens. Fundamental \\
\hline Filhos: & Não possui & 1 filho de 1 ano & Não possui \\
\hline Animais de estimação: & 1 cachorro & Não possui & Não possui \\
\hline Ocupação: & Trabalha e estuda & Trabalha & Aposentado \\
\hline Renda média familiar: & $\mathrm{R} \$ 3.000,00$ & $\mathrm{RS} 3.500,00$ & $R \$ 2.600,00$ \\
\hline Frequência na praça & Diariamente & 1 vez por semana & Duas vezes por semana \\
\hline Tempo que frequenta: & Mais de 3 anos & 5 anos & Mais de 50 anos \\
\hline Atividade praticada: & Fumar e conversar com amigos. & Comer hot dog e namorar & Conversar com amigo \\
\hline Praça Benedito Calixto & E 10 & E 11 & E 12 \\
\hline Sexo / Idade: & Mulher/ 23 anos & Mulher/ 31 anos & Homem/ 61 anos \\
\hline Bairro: & Pinheiros & Pinheiros & Taboão da Serra \\
\hline Tipo de moradia: & Apartamento & Apartamento & Apartamento \\
\hline Escolaridade: & Superior cursando & Superior completo & Ensino Médio \\
\hline Filhos: & Não possui & Não possui & 5 filhos de 11 a 38 anos \\
\hline
\end{tabular}


Quadro 1. Informações sobre os entrevistados de cinco praças públicas estudadas na cidade de São Paulo, SP (continuação),.

\begin{tabular}{|c|c|c|c|}
\hline Praça Benedito Calixto & E 10 & E 11 & E 12 \\
\hline Animais de estimação: & 1 cachorra & Não possui & Não possui \\
\hline Ocupação: & Trabalha e estuda & Trabalha & Trabalha \\
\hline Renda média familiar: & $\mathrm{R} \$ 10.000,00$ & RS $15.000,00$ & $\mathrm{R} \$ 2.000,00$ \\
\hline Frequência na praça & Diariamente & $\begin{array}{c}\text { De uma a } 3 \text { vezes por } \\
\text { semana }\end{array}$ & Diariamente \\
\hline Tempo que frequenta: & 7 anos & 4 anos & 5 anos \\
\hline Atividade praticada: & Passear com a cachorra & $\begin{array}{c}\text { Tomar sorvete em um } \\
\text { banco }\end{array}$ & Conversar com amigos \\
\hline Praça Novo Mundo & E 13 & E 14 & E 15 \\
\hline Sexo / Idade: & Mulher / 18 anos & Mulher/ 37 anos & Homem/ 73 anos \\
\hline Bairro: & Pa. Novo Mundo & Pa. Novo Mundo & Pa. Novo Mundo \\
\hline Tipo de moradia: & Casa & Casa & Apartamento \\
\hline Escolaridade: & Ensino médio & Superior completo & Primário \\
\hline Filhos: & Não possui & Não possui & 4 filhos adultos \\
\hline Animais de estimação: & 1 gato & 1 cachorro & Não possui \\
\hline Ocupação: & Desempregada & Trabalha & Aposentado \\
\hline Renda média familiar: & $\mathrm{R} \$ 1.000,00$ & RS 1.900,00 & $R \$ 3.500,00$ \\
\hline Frequência na praça & Diariamente & Diariamente & Até 2 vezes por semana \\
\hline Tempo que frequenta: & Mais de 3 anos & 10 anos & 32 anos \\
\hline Atividade praticada: & $\begin{array}{l}\text { Oferecer folhetos e orientações } \\
\text { religiosas com amiga }\end{array}$ & $\begin{array}{c}\text { Brincar com sobrinhos e } \\
\text { com cachorro }\end{array}$ & $\begin{array}{c}\text { Descansar após andar de } \\
\text { bicicleta }\end{array}$ \\
\hline
\end{tabular}

Uma alternativa para evitar o desgaste dos itens é sugerida pelos próprios frequentadores (E1 e E3), com a segmentação do espaço para perfis de público diferentes, como na Praça Franklin Roosevelt, onde a disputa pelo espaço é mais evidente devido ao conflito entre os Skatistas e os demais frequentadores. Esta separação de áreas diminuiria o conflito e previne o estrago dos itens existentes, como ocorre quando os Skatistas usam os bancos da praça para manobras. Outra solução sugerida pelos frequentadores é a presença de monitores nas praças, conforme relato de E14, para fiscalizar e inibir ações indesejadas e preservar a estrutura da praça.

\subsection{2. Área verde}

Apenas os frequentadores da Praça Franklin Roosevelt apontaram a falta de área verde como um ponto fraco do local, sem observações positivas neste quesito. Entretanto, 60\% dos entrevistados apontaram a área verde como ponto forte das praças e manifestaram ainda, o desejo de vê- la ampliada (6,6\%) e bem cuidada (6,6\%), como demonstrado na Quadro 3.

Foi observado que nenhum dos frequentadores da faixa etária 3 apontaram a área verde como uma motivação para frequentar a praça. Esta faixa etária também apresentou pouco entusiasmo em relação ao verde em outras respostas, indicando que pode não perceber o verde da mesma maneira que outras faixas etárias.

A presença de área verde, por seus benefícios gerados como sombra, frescor e tranquilidade, características atrativas para visita, corrobora com a afirmação de De Angelis et al. (2004) de que a população brasileira identifica a praça como área verde. Conforme exposto por Orth e Cunha (2000) e Oliveira e Mascaró (2007), a necessidade de contato com a natureza é sensível nos cidadãos de regiões altamente urbanizadas como São Paulo.

O sentimento de liberdade dá à praça a característica de um local de descompressão e relaxamento, associando-a com qualidade de vida (OLIVERIA; MASCARÓ, 2007; LOBODA; DE ANGELIS, 
Quadro 2. Percepção de frequentadores sobre a estrutura e equipamentos das praças estudadas: Franklin Roosevelt, Floriano Peixoto, Silvio Romero, Benedito Calixto e Novo Mundo.

\begin{tabular}{|c|c|c|}
\hline Praça & Análise & Percepção descrita \\
\hline \multirow{4}{*}{$\begin{array}{l}\text { Franklin } \\
\text { Roosevelt }\end{array}$} & Pontos fortes & E 3/ FR: Foi aberto mais espaço, valorizou muito aqui. \\
\hline & \multirow{3}{*}{ Pontos fracos } & $\begin{array}{l}\text { E 1/ FR: Era pra ser reformada como praça dos skatistas e ter um pouco de espaço também } \\
\text { pra lazer para outras pessoas que praticam outros esportes. }\end{array}$ \\
\hline & & $\begin{array}{l}\text { E 2/ FR: O cachorródromo devia ser cercado, bonitinho, assim aberto acaba ficando perigoso, } \\
\text { vai que algum escapa. }\end{array}$ \\
\hline & & $\begin{array}{l}\text { E 3/ FR: Deveria ter uma divisão de práticas esportivas (skate, pessoas idosas, crianças) ou } \\
\text { uma divisão de espaço equitativo, de acordo com a idade, de acordo com o perfil. }\end{array}$ \\
\hline \multirow{4}{*}{$\begin{array}{l}\text { Floriano } \\
\text { Peixoto }\end{array}$} & Pontos fortes & E.4/ FP: Está boa, bem cuidada. \\
\hline & \multirow{3}{*}{ Pontos fracos } & $\begin{array}{l}\text { E 4/ FP: Gostaria que tivesse playground pra criança. Tem que as grades que cercam os } \\
\text { gramados da praça. }\end{array}$ \\
\hline & & $\begin{array}{l}\text { E 5/ FP: Era pra ter banheiro aqui, não tem. Acho que faltam aqueles aparelhos de ginástica } \\
\text { e mais os bancos. No momento não dá pra ter lazer porque não tem espaço e eles (gestores) } \\
\text { não cuidam bem. }\end{array}$ \\
\hline & & $\begin{array}{l}\text { E 6/ FP: A gente se senta na mureta em torno de uma árvore, porque não tem um banco, } \\
\text { deveriam pensar nisso. }\end{array}$ \\
\hline \multirow{4}{*}{ Silvio Romero } & Pontos fortes & Não foi observado. \\
\hline & \multirow{3}{*}{ Pontos fracos } & E 5/ SR: Os bancos poderiam ser mais limpos, aqui são sujos. \\
\hline & & $\begin{array}{l}\text { E 7/ SR: Parquinho para as crianças e ter mais coisas de lazer, igual nas praças dos outros } \\
\text { bairros. }\end{array}$ \\
\hline & & $\begin{array}{l}\text { E 8/ SR: Podia ter equipamentos de ginástica para idoso. Ter alguma coisa para as crianças } \\
\text { também. }\end{array}$ \\
\hline \multirow{5}{*}{$\begin{array}{l}\text { Benedito } \\
\text { Calixto }\end{array}$} & \multirow{2}{*}{ Pontos fortes } & $\begin{array}{l}\text { E 10/ BC: Essa coisa de árvores, sombrinha. Todo mundo que vem cuida. Então que mantenha } \\
\text { esse cuidado, sabe? Porque é gostoso frequentar um lugar mais limpo. }\end{array}$ \\
\hline & & $\begin{array}{l}\text { E 11/ BC: Ampliaram a quadra, colocaram coisas para ginástica de idoso, reformaram o } \\
\text { parquinho das crianças e colocaram wi-fi, então tem várias coisas legais. }\end{array}$ \\
\hline & \multirow{3}{*}{ Pontos fracos } & $\begin{array}{l}\text { E 10/ BC: Sinalizar um pouco melhor, eu acho que fecha cedo as barraquinhas, antes das seis } \\
\text { começam a guardar as coisas. }\end{array}$ \\
\hline & & $\begin{array}{l}\text { E 11/ BC: Ter mais lugar pra sentar, nem que fosse para tirar uma ou outra barraca (da feira de } \\
\text { antiguidades). Colocar um bebedouro, alguma coisa assim. }\end{array}$ \\
\hline & & $\begin{array}{l}\text { E 12/ BC: Que fosse mais limpa, mais cuidada. Tem a associação, mas o recurso é pouco. Que } \\
\text { fosse informatizada. }\end{array}$ \\
\hline \multirow{4}{*}{ Novo Mundo } & Pontos fortes & Não foi observado. \\
\hline & \multirow{3}{*}{ Pontos fracos } & $\begin{array}{l}\text { E 13/ NM: Aqui é horrível. Não tem nada pra fazer. Tá tudo mal cuidado e quebrado. Gostaria } \\
\text { que voltasse a ter os aparelhos de ginástica, tinha aqui e quebraram tudo. }\end{array}$ \\
\hline & & $\begin{array}{l}\text { E 14/ NM: Tem que ter uma colaboração de todos mas também um monitoramento. Mais } \\
\text { aparelhos de ginástica, os que tinham aqui sumiram. }\end{array}$ \\
\hline & & $\begin{array}{l}\text { E 15/ NM: Mais lazer para crianças. As grades estão quebradas. Um perigo correr pra pegar } \\
\text { uma bola e o carro atropelar. Para nossa idade (idoso) é ruim por ser muito acidentado o } \\
\text { terreno, ladeira. }\end{array}$ \\
\hline
\end{tabular}

2005; HAQ, 2011). Por outro lado, a visão da praça como espaço livre e verde é contraditória com o fato de se constituir de um espaço cercado e de acesso limitado (DE ANGELIS et al., 2005; MOMMSCHULT et al., 2013).

\subsubsection{Segurança}

A sensação de insegurança foi apontada como ponto fraco pelos entrevistados, pela falta de policiamento e iluminação ou pela presença de moradores de rua, usuários de drogas e vandalismo no local (Quadro 4).

O policiamento não garante a monitoria e nem reduz os danos estruturais da praça, na visão dos frequentadores, a exemplo relatos de E5 e E8, que acham os horários sem policiamento pontos fracos. A iluminação foi um ponto forte encontrado na percepção de E 10, que frequenta a Praça Benedito Calixto até meia noite. 
Quadro 3. Percepção dos frequentadores sobre a área verde das praças estudadas: Franklin Roosevelt, Floriano Peixoto, Silvio Romero, Benedito Calixto e Novo Mundo.

\begin{tabular}{|c|c|c|}
\hline Praça & Análise & Percepção descrita \\
\hline \multirow{4}{*}{$\begin{array}{l}\text { Franklin } \\
\text { Roosevelt }\end{array}$} & Pontos fortes & Não foi observado \\
\hline & \multirow{3}{*}{ Pontos fracos } & $\begin{array}{l}\text { E 1/ FR: A praça é aberta e não tem sombra. Se tivesse umas árvores grandes seria mais } \\
\text { confortável nos dias de sol. }\end{array}$ \\
\hline & & $\begin{array}{l}\text { E 2/ FR: Eu não considero essa praça um lugar verde para a cidade, precisa melhorar, colocar } \\
\text { mais árvores, ficou muito concreto. }\end{array}$ \\
\hline & & $\begin{array}{l}\text { E 3/ FR: Eu não acho que São Paulo tenha área verde suficiente em lugar nenhum. Então aqui } \\
\text { também não tem. Mas se aumentasse mesmo seria muito bom. }\end{array}$ \\
\hline \multirow{4}{*}{$\begin{array}{l}\text { Floriano } \\
\text { Peixoto }\end{array}$} & \multirow{2}{*}{ Pontos fortes } & $\begin{array}{l}\text { E 4/ FP: Aqui tem árvores, bate sombra. O bom aqui é isso (área verde), que dá vida para a } \\
\text { praça. }\end{array}$ \\
\hline & & $\begin{array}{l}\text { E 6/ FP: Está mais bonita e cuidada. Essas árvores sempre existiram, mas estão cuidando mais } \\
\text { agora. Você senta aqui pra descansar, principalmente no calor. }\end{array}$ \\
\hline & \multirow[b]{2}{*}{ Pontos fracos } & E 4/ FP: Ali na frente tem lugar pra sentar, mas não bate sombra. \\
\hline & & $\begin{array}{l}\text { E 5/ FP: Deveria ser (uma área verde), mas não tem quase nada e deveria cuidar melhor" Seria } \\
\text { bom preservar e aumentar, né?. }\end{array}$ \\
\hline \multirow{4}{*}{ Silvio Romero } & \multirow[b]{2}{*}{ Pontos fortes } & E 7/ SR: É calmo aqui também, sossegado, tem as árvores. \\
\hline & & $\begin{array}{l}\text { E 8/ SR: Tem esse ar, esse clima, essas árvores ajudam um pouco. Sem essa praça nós } \\
\text { perderíamos um espaço assim com sombra, com esse clima fresco. }\end{array}$ \\
\hline & \multirow[b]{2}{*}{ Pontos fracos } & E 8/ SR: Ter um gramado mais bonito, plantar mais árvores. \\
\hline & & $\begin{array}{l}\text { E 9/ SR: Tinha que ser preservado e ser bem cuidado, dar uma renovação, mas ninguém } \\
\text { cuida, ninguém faz nada. Se não é a chuva pra dar uma molhada. }\end{array}$ \\
\hline \multirow{3}{*}{$\begin{array}{l}\text { Benedito } \\
\text { Calixto }\end{array}$} & \multirow[b]{2}{*}{ Pontos fortes } & E 10/ BC: Tem mais árvores, mais natureza, te dá mais uma liberdade. \\
\hline & & $\begin{array}{l}\text { E 11/ BC: É um dos poucos lugares onde eu moro que tem árvore. Se a praça deixasse de } \\
\text { existir eu ia ter que procurar outro lugar que fornecesse pelo menos um lugar com sombra e } \\
\text { árvore, o que não tem na região. Morar em apartamento antigo que não tem árvore é o que a } \\
\text { praça substitui pra mim. }\end{array}$ \\
\hline & Pontos fracos & Não foi observado. \\
\hline \multirow{4}{*}{ Novo Mundo } & \multirow{3}{*}{ Pontos fortes } & $\begin{array}{l}\text { E 13/ NM: Eu acho que a área verde daqui é muito bonita e é a única coisa boa que tem } \\
\text { agora. }\end{array}$ \\
\hline & & $\begin{array}{l}\text { E 14/ NM: Nós temos que preservar um lugar desses, com árvores, com os animais que ainda } \\
\text { restam. Esse verde aqui é importante para a população e tão perto de casa. }\end{array}$ \\
\hline & & $\begin{array}{l}\text { E 15/ NM: Uma praça sem árvore não é uma praça, se tirar as árvores vai ficar um espaço } \\
\text { vazio e não tem sentido mais. }\end{array}$ \\
\hline & Pontos fracos & $\begin{array}{l}\text { E 15/ NM: Deveria ser mais cuidada, mais poda nas árvores grandes, cuidado com o mato. Não } \\
\text { tem muito cuidado com a natureza. Acho que dá pra melhorar a praça sem acabar com esse } \\
\text { verde. }\end{array}$ \\
\hline
\end{tabular}

A segurança e boa manutenção também é algo desejado e visto como necessário para visitar a praça, segundo Momm-Schultet et al. (2013) como algo necessário para se manter a frequencia da população neste espaço. A estrutura da praça e seus elementos são importantes para a escolha da prática de terminadas atividades, mas não é determinante. Conforme já afirmado por Mendonça (2007), a população pode se apropriar do espaço e adequá-lo as suas necessidades.

\subsubsection{Localização, espaço e acesso}

A localização, espaço e acesso da praça foram citados como elementos motivadores na decisão de visitar a praça. A proximidade com a residência ou trabalho representou $60 \%$ da motivação dos entrevistados, sendo a localização um fator de uso do local. Outros motivos de escolha como opção dos outros entrevistados estão associados ao acesso (6,6\%) e aproveitamento do local (E1, E5 e E9). Em relação à localização, o fato de as praças serem próximas de casa ou do trabalho foi o mais citado, indicando que as praças são frequentadas principalmente pelos moradores do bairro em que se localiza. 
Quadro 4. Percepção dos frequentadores sobre a segurança das praças estudadas: Franklin Roosevelt, Floriano Peixoto, Silvio Romero, Benedito Calixto e Novo Mundo.

\begin{tabular}{|c|c|c|}
\hline Praça & Análise & Percepção descrita \\
\hline \multirow{3}{*}{$\begin{array}{l}\text { Franklin } \\
\text { Roosevelt }\end{array}$} & \multirow[b]{2}{*}{ Pontos fortes } & E 1/ FR: A única coisa boa aqui que mudou é que agora tem policiamento \\
\hline & & $\begin{array}{l}\text { E 3/ FR: Ficou um lugar policiado, eu não digo seguro, mas antes era abandonada, aqui havia } \\
\text { um antro de promiscuidade e sujeira. }\end{array}$ \\
\hline & Pontos fracos & Não foi observado. \\
\hline \multirow{3}{*}{$\begin{array}{l}\text { Floriano } \\
\text { Peixoto }\end{array}$} & Pontos fortes & E 4/ FP: Acho que a praça é segura sim. Não tem muito mendigo não. \\
\hline & \multirow{2}{*}{ Pontos fracos } & $\begin{array}{l}\text { E 5/ FP: Tem a poíicia, mas dependendo do horário ela fica mais. Se tivessem guardas para } \\
\text { cuidar, seria bom pra evitar vândalos. Ainda não tem segurança. }\end{array}$ \\
\hline & & $\begin{array}{l}\text { E 6/ FP: Tem muita gente que é indesejável, não devia ter morador de rua, tem que levar eles } \\
\text { pra um lugar certo. }\end{array}$ \\
\hline \multirow{4}{*}{ Silvio Romero } & Pontos fortes & Não foi observado. \\
\hline & \multirow{3}{*}{ Pontos fracos } & E 7/ SR: Tem a base da polícia próxima, mas sei lá, é muita droga aqui. \\
\hline & & $\begin{array}{l}\text { E 8/ SR: Se tivesse mais segurança. Tem a polícia, mas dependendo do horário ela fica mais } \\
\text { abandonada. }\end{array}$ \\
\hline & & $\begin{array}{l}\text { E 9/ SR: Nem venho aqui de noite. Além de morador de rua tem usuário de droga. Aqui eles } \\
\text { não põem equipamentos de ginástica e eles quebram tudo. }\end{array}$ \\
\hline \multirow{3}{*}{$\begin{array}{l}\text { Benedito } \\
\text { Calixto }\end{array}$} & \multirow{2}{*}{ Pontos fortes } & $\begin{array}{l}\text { E 10/ BC. No início ela não era tão iluminada, mas hoje eu já fico até meia noite com a minha } \\
\text { cachorra e dá pra ficar normal. Era mais "chatinho" de ficar por aqui. }\end{array}$ \\
\hline & & $\begin{array}{l}\text { E 11/ BC: Antes achava que era mal frequentada, porque talvez tivesse visto um ou outro } \\
\text { morador de rua, mas hoje ela está mais agradável, mais gente leva a família. }\end{array}$ \\
\hline & Pontos fracos & Não foi observado. \\
\hline \multirow{3}{*}{ Novo Mundo } & Pontos fortes & Não foi observado. \\
\hline & \multirow{2}{*}{ Pontos fracos } & $\begin{array}{l}\text { E 13/ NM: Não indicaria, aqui é horrível. Não tem nada pra fazer. Tudo mal cuidado e } \\
\text { quebrado. }\end{array}$ \\
\hline & & $\begin{array}{l}\text { E 14/ NM: Tem que ter também alguém pra fazer vistoria, estar cuidando do nosso patrimônio. } \\
\text { Tem pessoas que não tem consciência. }\end{array}$ \\
\hline
\end{tabular}

Um dos pontos positivos da praça no ambiente urbano, como um tipo de espaço de fidelização, é que pode ser pulverizado pela cidade, levando área verde e de lazer para o local de residência da população. Assim, diminui a necessidade de deslocamento para outras regiões, reafirmando a ideia de Lee e Maheswaran (2011), da praça como espaço verde que pode facilmente se distribuido pela malha urbana. O fato de ser uma área plana também foi apontado por um dos entrevistados (E15), como algo positivo para os idosos, que tem dificuldade de locomoção em ambientes acidentados (Figura 3).

O entorno é percebido pelos frequentadores como parte e/ou extensão da praça, como as lojas, restaurantes e outros estabelecimentos encontrados ao redor. Aqui o entrevistado E9 diz que os motivos para ir à praça variam, mas que ir ao banco, que se encontra em frente à praça, é um motivo recorrente para ir ao local.

\subsubsection{Lazer e descanso}

Alguns elementos estruturais da praça funcionam como atrativo, como espaço para cachorro e playground (Figura 4). Do total de entrevistados, $33,3 \%$ vão à praça para levar os animais de estimação, 20 \% para descansar, $13 \%$ para sair com a família e outras razões, como descrito por E6, refrescar. Um dos benefícios gerados pela área verde faz com que os frequentadores a procurem para descansar, como demonstrado nos comentários sobre sombra e frescor do local (E6).

Descansar, passear com cachorro e levar crianças para brincar indica a visão da praça como uma área de lazer barata, ideal para a prática de atividades de lazer simples e que fazem parte do cotidiano das pessoas, que não necessitam de estrutura, equipamentos ou preparações muito elaboradas. Em nenhuma das visitas foi notada a presença de pessoas com necessidades especiais, mas a presença de idosos foi constante em todas as praças. 


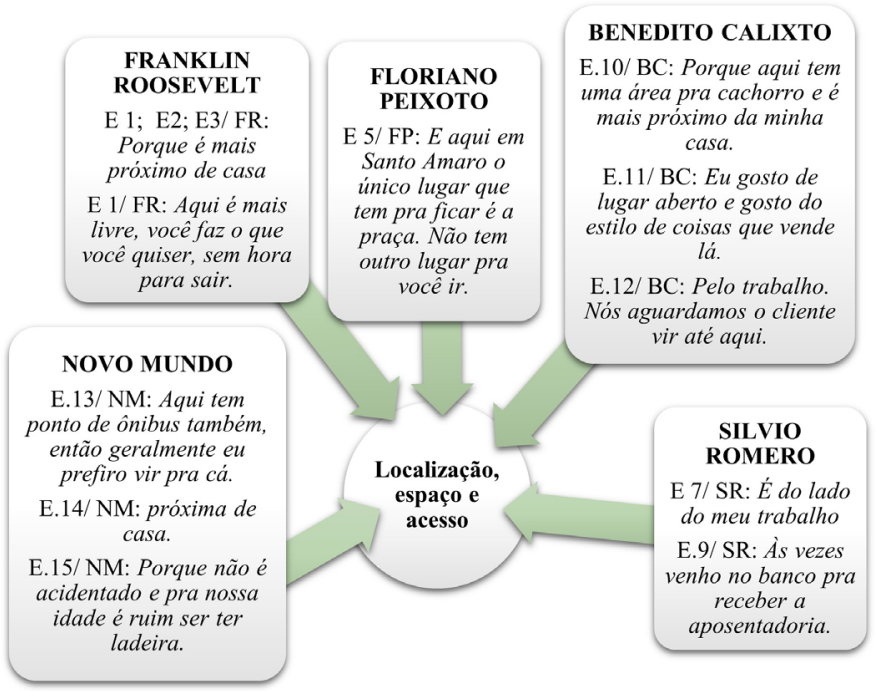

Fig. 3. Motivações para uso das cinco praças de acordo com a percepção de frequentadores.

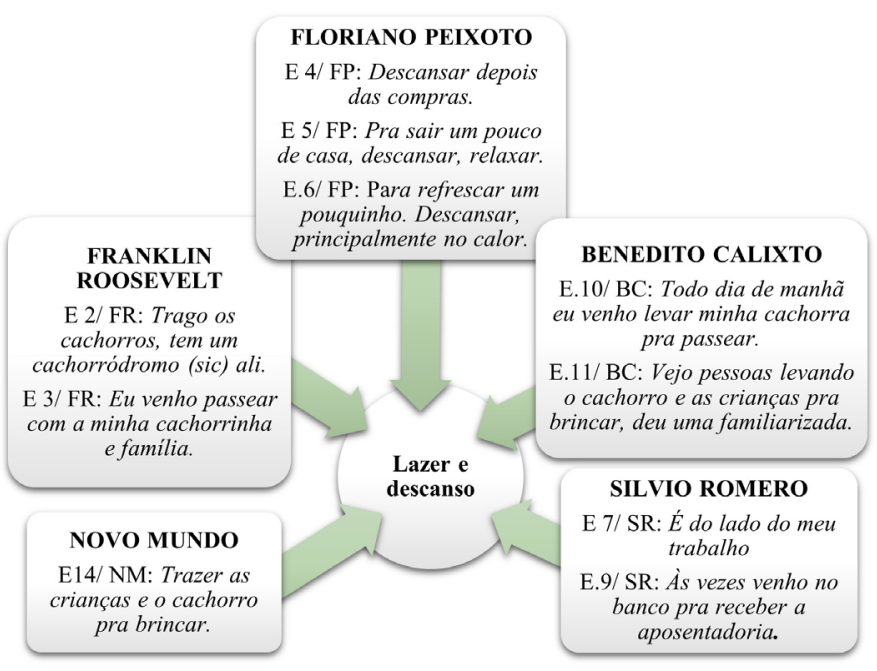

Fig. 4. Motivações de lazer e descanso de acordo com a percepção de frequentadores, nas cinco praças estudadas.

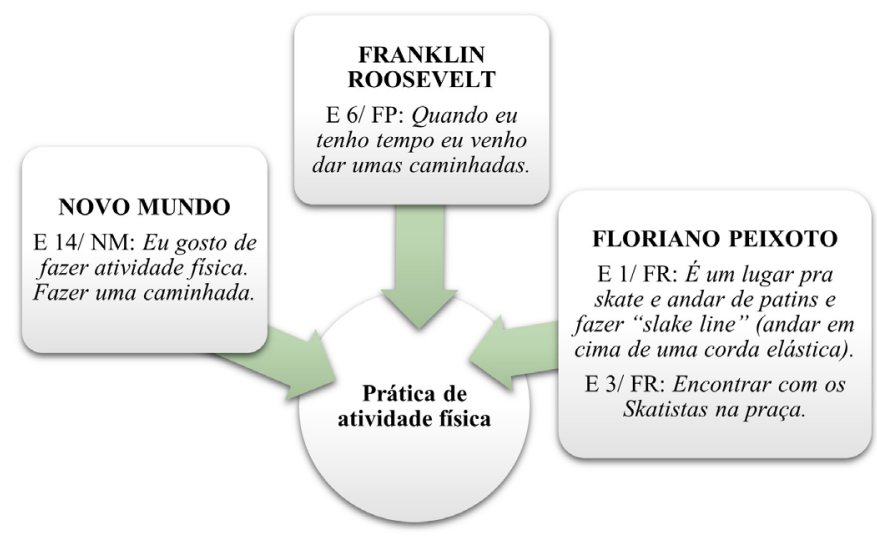

Fig. 5. Motivações de lazer e descanso de acordo com a percepção de frequentadores, nas cinco praças estudadas.
Filhos e animais de estimação são motivos que levam as pessoas a frequentarem áreas públicas urbanas, sendo por isso importante consultar tais perfis de frequentadores (IOJÃ et al., 2011). A percepção da praça como local ideal para brincar foi discutido por Thompson (2002, 2008) e Haq (2011), assim como idosos e pessoas com necessidades especiais ou baixas condições financeiras. No entanto, outros padrões não podem ser afirmados pelas percepções dos frequentadores, que tem perfis financeiros bem variados, refutando a ideia de local para pessoas desprovidas financeiramente. Praças atraem perfis variados da população e busca atendê-los de forma equitativa.

\subsubsection{Atividade física e esporte}

Praticar atividade física ou esportes e atividades de lazer é outra motivação relatada, principalmente nas praças Franklin Roosevelt, Floriano Peixoto e Novo Mundo, conforme a Figura 5.

Além dos idosos, as demais faixas etárias frequentam os locais para a prática de atividades físicas e esportes, conforme relatos de E1 e E14. A faixa etária 1 prefere a prática de esportes enquanto as demais preferem caminhada e fazer exercícios em aparelhos de ginástica.

A existência de elementos que permitam a permanência de pessoas em espaços públicos é uma maneira de fazer com que os benefícios proporcionados por estes espaços possam ser sentidos pela população. Como exemplo, o uso da praça para a prática de exercícios e atividades esportivas reforça a função desta como local de lazer e de espaço que contribui para a melhoria da saúde e qualidade de vida populacional (OLIVEIRA; MASCARÓ, 2007; LOBODA; DE ANGELIS, 2005; HAQ, 2011). No presente trabalho a praça é percebida como um espaço voltado ao lazer e prática de exercícios físicos, características presentes em alguns conceitos de praça.

\subsubsection{Compras e alimentação}

As Praças Benedito Calixto e Floriano Peixoto contam com feirinhas de antiguidade, de artesanato 


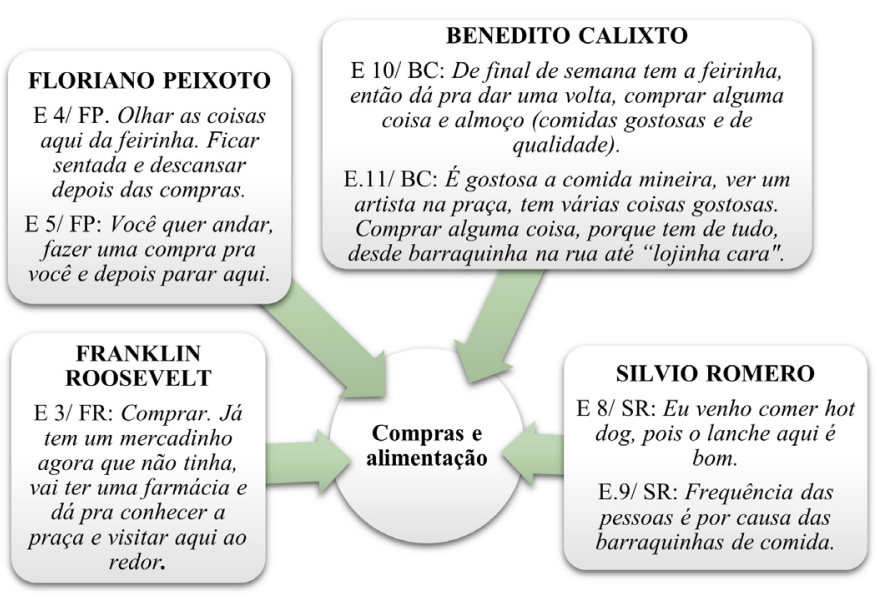

Fig. 6. Motivações de compras e alimentação nas cinco praças públicas estudadas.

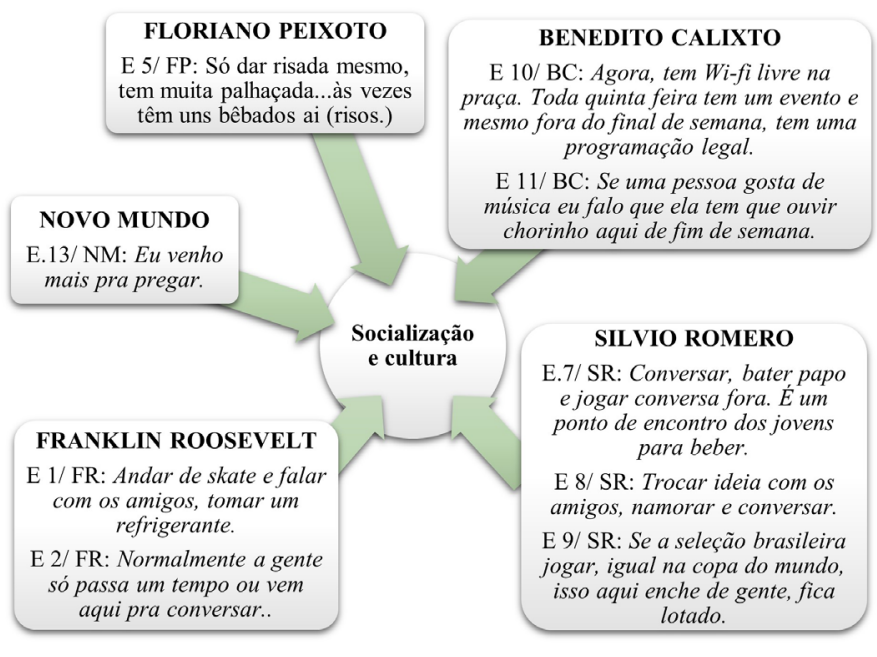

Fig. 7. Motivações de socialização e cultura em cinco praças estudadas na cidade de São Paulo. e gastronomia, que atraem os frequentadores, a exemplo do E8, que consome lanches como Hot Dog na Praça Sílvio Romero (Figura 6). Portanto, consumir alimentos foi outra motivação relacionada ao lazer e socialização, já que é feito na companhia de amigos, conforme relatos de E8 e E10. Também reforça a percepção do entorno, visto que ir a um restaurante próximo é uma prática comum após visitar a praça.

A entrevistada E11 afirmou ir à Praça Benedito Calixto para evitar ir ao Shopping, encontrando produtos diferenciados. Neste caso a tranquilidade da praça e a presença de lojas com produtos diferentes dos encontrados nos Shoppings são um dos pontos de predileção apontados. A realização de compras nas feirinhas, que oferecem artesanatos, foi outra motivação, relatada por E4, E10 e E11.

De Angelis et al. (2005) fizeram menção às compras como uma das funções de local de comércio da praça, também apontado como uma boa alternativa ao Shopping Center. Este é um dos principais concorrentes das áreas públicas de lazer e de que as praças podem ser atrativas o suficiente para concorrer com tais opções privadas de comércio e lazer. Esta integração das praças com o entorno pode ser uma alternativa para este feito (GOMES, 2008; DE ANGELIS et al., 2005; THOMPSON, 2002).

\subsubsection{Socialização e cultura}

Na Praça Benedito Calixto ocorrem apresentações culturais, como grupo de chorinho que foi citado por E11 (Figura 7). Isto indica que a realização de eventos e atividades culturais e de lazer são bem recebidas pelos frequentadores das praças e que pode funcionar bem para atrair os habitantes para este local, incentivando sua ocupação e uso, dando vida à praça. Ambas as entrevistadas sugeriram a visitação na feirinha de antiguidades e assistir às apresentações de chorinho como algo que indicariam a um amigo que quisesse visitar a praça.

Nas praças estudadas a interação social encontrada é voltada para lazer, encontrar amigos, conversar com vizinhos e diversão familiar. Enquanto que na história das praças a interação social era

Fig. 8. Importância do espaço e sentimento de pertencimento pelos frequentadores das praças. 
descrita por manifestações políticas, religiosas, comerciais, entre outras. Segundo Caldeira (2007) e Silva (2012), apontando a adaptação ao cotidiano da sociedade atual, mas mantendo algumas funções tradicionais, como citado por E13, que frequenta a praça para pregar. Dessa forma, a Praça Novo Mundo é frequentada por este público aos finais de semana, onde é comum membros de igrejas evangélicas realizarem pregações e apresentações musicais. Embora possua uma igreja em seu espaço, os frequentadores da Praça Silvio Romero não associaram comemorações ou encontros religiosos ao local. Nos arredores da Praça Franklin Roosevelt há uma igreja que realiza festas religiosas, mas numa área da igreja que não é contígua à praça.

\subsubsection{Topofilia}

Apesar desta percepção individual, pessoas de um determinado grupo social podem apresentar percepções semelhantes e isso faz com que a análise da percepção, da topofilia, de grupos seja viável. Os sentimentos relatados pelos frequentadores das praças são positivos, refletindo apego e carinho, conforme relatos contidos a Figura 8.

Verificou-se na fala dos entrevistados manifestação de pertencimento, visto ser o cenário para encontro de amigos, vizinhos e namorados, onde se pode conversar e se divertir juntos. Perder a praça seria o mesmo que perder esta interação social, indicando que a presença de pessoas e a interação decorrente do encontro é algo desejado e esperado numa praça, como parte da identidade da mesma, ideia afirmada por De Angelis et al. (2005).

A importância da praça também é associada com liberdade, saudosismo e até desapego. Uma destas demonstrações é a sensação de que a praça faz parte do cotidiano dos frequentadores, como comer algo ou encontrar os amigos, tornando a visita à praça como algo rotineiro, conforme relatos de E5, E8 e E10. O saudosismo também foi manifestado, como exemplo de E11 afirmando que a praça traz lembranças da infância e por isso levava seus sobrinhos para que eles tivessem experiências parecidas com as dela. Outro tipo de saudosismo foi manifestado pela feira de antiguidades da Praça Benedito Calixto, relatado por E10. O contato com os objetos da feira provocou lembranças da infância e de tempos passados.

O verde é considerado como identidade da praça e as boas sensações pela sombra e clima fresco são algo que as pessoas buscam ao visitá-la. Perder a área verde é perder este contato com a natureza, conforme relatos de E10 e E14.

A topofilia é o sentimento de apego que um indivíduo sente em relação a um lugar e que a percepção do ambiente é individual e pode provocar sentimentos diferentes em relação ao espaço, criando um laço afetivo entre este indivíduo e o ambiente. Estudos de percepção ambiental afirmam que visitantes podem ter uma percepção diferente dos moradores locais e que a idade é considerada uma variável que influencia na percepção, uma vez que esta é construída ao longo do tempo de vida e experiências (TUAN, 2012).

O uso da praça para encontrar as pessoas do bairro e vizinhança indica a percepção do local como ponto de interação social, conforme conceitos propostos por Mendonça (2007) e Silva (2012). Segundo De Angelis et al. (2005) a função de espaço de interação social deve ser a principal característica das praças, que pode não ser vista com facilidade em grandes centros urbanos, mas que é notada de forma mais evidente em cidades do interior brasileiro.

A valorização do espaço para seus frequentadores pode despertar um maior cuidado e preservação do espaço pelos mesmos (COSTA; COLESANTI, 2011), que segundo De Angelis et al. (2005) é uma postura esperada da população que deve cobrar investimentos do poder público de em áreas de verdes e de lazer. Uma relação mais estreita com estes espaços públicos pode resultar em uma postura participativa da população, que passa a se envolver nas questões de planejamento e políticas públicas destes espaços (JACOBI, 2003; COSTA; COLESANTI, 2011).

Por fim, a praça deve ter uma estrutura que amplie a permanência do visitante em seu espaço e também traga benefícios gerados por ela, segundo 
De Angelis et al. (2005), Haq (2011) e Thompson (2002). Na visão de seus frequentadores a praça tem a função de promover contato com a natureza e bem-estar por meio da prática de atividades de lazer, cultura, interação social e prática de atividade física e deve estar inserida no cotidiano da população. Esta percepção enquadra a praça nos conceitos de área verde trazidos por Benini e Martin (2011), Caporusso e Matias (2008) e Haq (2011), reafirmando a importância deste espaço na cidade de São Paulo.

\section{Considerações finais}

Considera-se que o perfil dos frequentadores das praças possui características diferentes. Estes espaços públicos são locais que atraem perfis socioeconômicos variados (idade, escolaridade e renda) da população paulistana, uma vez que que é oferecida infraestrutura abrangente. De acordo a percepção e uso de frequentadores pode ser considerado nove grupos de categorias relevantes para o planejamento, manutenção e uso de praças. Dentre eles, destacam-se: 1. Estrutura e equipamentos; 2. Área verde; 3. Segurança; 4. Localização, espaço e acesso; 5. Lazer e descanso; 6. Atividade física e esporte; 7. Compras e alimentação; 8. Socialização e cultura; e 9. Topofilia.

Os frequentadores das praças estudadas (Floriano Peixoto, Franklin Roosevelt, Benedito Calixto, Sílvio Romero e Novo Mundo) percebem e utilizam as praças de maneiras diferentes. As percepções das praças pelos frequentadores podem auxiliar na criação de projetos bases, com elementos semelhantes, que atendam a essas expectativas em comum. Mas que sejam flexíveis em outros pontos para que possam ser adequados a necessidades específicas de certos bairros e tipos de praças.

A geografia da praça também devem ser levada em conta como elemento importante capaz de afastar alguns perfis, como os idosos. Adequações devem ser consideradas para minimizar as dificuldades que este público possa encontrar ao visitar a praça, como piso e acesso, também importante para pessoas portadoras de deficiência.
Deve-se também levar em conta o desejo e a prática de um momento de lazer com o animal de estimação. Essa é uma tendência a ser considerada na criação de novas praças, como exemplo dos "cachorródromos" já presentes em algumas praças onde o entorno é composto de prédios como moradia.

A presença de bancos, lixeiras, banheiros e outros elementos que prolonguem a estadia do visitante na praça e aumente seu conforto ao visitar o espaço também é algo desejado pela população e deve ser levada em conta pela gestão. A zeladoria compartilhada é algo positivo e desejado pelos entrevistados, que auxilia na manutenção por parte dos gestores. Também é desejável o acesso à internet livre nas praças, adaptando a tecnologia em espaços públicos e atraindo novos fequentadores.

A integração entre a praça e os estabelecimentos que as cercam é um ponto positivo de atração, podendo ser competitiva com outros espaços de lazer privados, como shopings. A realização de eventos como feiras e apresentações culturais também promove uma maior integração da mesma com o entorno, agregando valor ao espaço de forma integrada. Este espaço não deve ser rígido, mas flexível para acompanhar aos anseios da população da cidade, agregando perfis diversos, sem conflitos.

\section{Referências}

BARROS, M. V. F.; VIRGILIO, H. Praças: espaços verdes na cidade de Londrina. Geografia, Londrina, v. 12, n. 1, p. 533-544, 2010.

BENCHIMOL, J. F.; LAMANO-FERREIRA, A. P. N. Distribuição de Praças Públicas na Cidade de São Paulo, SP. In: BENINI, S.M.; ROSIN, J.A.R.G. (Org.). Estudos Urbanos: uma abordagem interdisciplinar da cidade contemporânea. $1^{a}$ ed. Tupã, SP: ANAP, 2015, p. 291-306.

BENCHIMOL, J. F. et al. Decentralized management of public squares in the city of São Paulo, Brazil: Implications for urban green spaces. Land Use

Policy, Online, v. 63, p. 418-427, 2017. 
BENINI, S. M.; MARTIN, E. S. Decifrando as áreas verdes públicas. Formação, Online, v. 2, n. 17, 2010.

CALDEIRA, J. M. A praça brasileira: Trajetória de um espaço urbano: origem e modernidade. Instituto de Filosofia e Ciências Humanas Universidade de Campinas, Campinas, 2007.

CAPORUSSO, D.; MATIAS, L. F. Áreas verdes urbanas: avaliação e proposta conceitual. In: ANAIS DO I SIMPÓSIO DE PÓS-GRADUAÇÃO EM GEOGRAFIA DO ESTADO DE SÃO PAULO, São Paulo, p. 71-87, 2008.

COSTA, R. G. S; COLESANTI, M. M. A contribuição da percepção ambiental nos estudos das áreas verdes. RA'E GA-O Espaço Geográfico em Análise, Curitiba, v. 22, 2011.

DE ANGELIS, B. L. D. et al. Avaliação das praças de Maringá, Estado do Paraná, Brasil. Acta Scientiarum Agronomy, Maringá, v. 27, n. 4, p. 629-638, 2008.

DE ANGELIS, B. L. D; CASTRO, R. M.; DE ANGELIS NETO, G. D. Metodologia para levantamento, cadastramento, diagnóstico e avaliação de praças no Brasil. Engenharia Civil, Maringá, v. 4, n. 1, p. 57-70, 2004.

DORIGO, T. A.; LAMANO-FERREIRA, A. P. N. Contribuições da Percepção Ambiental de Frequentadores sobre Praças e Parques no Brasil (2009-2013): Revisão Bibliográfica. Revista de Gestão Ambiental e Sustentabilidade. v. 4, p. 3145, 2015.

DUARTE, R. Entrevistas em pesquisas qualitativas. Educar em Revista, Curitiba, n. 24, p. 213-225, 2004.

GOMES, M. A. S. De largo a jardim: praças públicas no Brasil-algumas aproximações. Estudos Geográficos: Revista Eletrônica de Geografia. Rio Claro, v. 5, n. 1, p. 101-120, 2008.

HAQ, S. M. A. Urban green spaces and an integrative approach to sustainable environment. Journal of
Environmental Protection, Online, v. 2, n. 05, p. 601, 2011.

HARDER, I. C. F.; RIBEIRO, R. C. S.; TAVARES, A. R. Índices de área verde e cobertura vegetal para as praças do município de Vinhedo, SP. Revista Árvore, Viçosa, v. 30, n. 2, p. 277-282, 2006.

IOJĂ, C. I. et al. Dog walkers' vs. other park visitors' perceptions: The importance of planning sustainable urban parks in Bucharest, Romania. Landscape and Urban Planning, Online, v. 103, n. 1, p. 74-82, 2011.

JACOBI, P. R. Espaços públicos e práticas participativas na gestão do meio ambiente no Brasil. Sociedade e Estado, Brasilia, v. 18, n. 1-2, p. 315-338, 2003.

JIM, C. Y.; CHEN, W. Y. External effects of neighbourhood parks and landscape elements on high-rise residential value. Land Use Policy, Online, v. 27, n. 2, p. 662-670, 2010.

LAMANO-FERREIRA, A. P. N. et al. Áreas Verdes Urbanas: conceitos, desafios e estratégias. In: CONSTANTINO, N. R. T.; ROSIN, J. A. R. G.; BENINI, S. M. (Org.). Paisagem: natureza, cultura e o imaginário. $1^{a}$ ed. Tupã: ANAP, 2017, v. 1, p. 13-34.

LAREDO, R.; SOMEKH, N. Gestão compartilhada na manutenção dos espaços públicos da cidade: Um olhar sobre a subprefeitura de Pinheiros em São Paulo. Revista Nacional de Gerenciamento de Cidades. Tupã, v. 1, n. 4, p. 08-14, 2014.

LEE, A. C. K; MAHESWARAN, R. The health benefits of urban green spaces: a review of the evidence. Journal of Public Health, Oxford, v. 33, n. 2, p. 212222, 2011.

LINHARES DE SOUZA, A. et al. Diagnóstico quantitativo e qualitativo da arborização das praças de Aracaju, SE. Revista Árvore, Viçosa, v. 35, n. 6, p. 1253-1263, 2011.

LO, A. Y. H; JIM, C. Y. Differential community effects on perception and use of urban greenspaces. Cities, 
Online, v. 27, n. 6, p. 430-442, 2010.

LOBODA, C. R.; DE ANGELIS, B. L. D. Áreas verdes públicas urbanas: conceitos, usos e funções. Ambiência, Guarapuava, v. 1, n. 1, p. 125-139, 2009.

MENDONÇA, E. M. S. Apropriações do espaço público: alguns conceitos. Estudos e Pesquisas em Psicologia, Online, v. 7, n. 2, p. 0-0, 2007.

MOMM-SCHULT, S. I. et al. Integration of urban and environmental policies in the metropolitan area of São Paulo and in Greater London: the value of establishing and protecting green open spaces. International Journal of Urban Sustainable Development, v. 5, n. 1, p. 89-104, 2013.

OLIVEIRA, L. A; MASCARÓ, J. J. Análise da qualidade de vida urbana sob a ótica dos espaços públicos de lazer. Ambiente construído, Online, v. 7, n. 2, p. 59-69, 2007.

ORTH, D. M.; CUNHA, R. D. C. Praças e áreas de lazer como ambiente construído influenciando na qualidade de vida urbana. ENTAC, Salvador, v. 1, p. 474-475, 2000.

SANTOS, M. O. et al. Percepção Ambiental sobre s Arborização Urbana no Bairro Santa Tereza, Tefé, Amazonas, Brasil. RA'E GA-O Espaço Geográfico em Análise, Curitiba, v. 44, p. 231-241, 2018.

SHACKLETON, C. M.; BLAIR, A. Perceptions and use of public green space is influenced by its relative abundance in two small towns in South Africa. Landscape and Urban Planning, Online, v. 113, p. 104-112, 2013.

SILVA, J. A. Direito Urbanístico Brasileiro. São Paulo: Malheiros. 2012, v. 201.

SUSHINSKY, J. R. et al. How should we grow cities to minimize their biodiversity impacts?. Global Change Biology, Online, v. 19, n. 2, p. 401-410, 2013.

THOMPSON, C. W. Urban open space in the 21st century. Landscape and urban planning, Online, v. 60, n. 2, p. 59-72, 2002.

THOMPSON, C. W.; ASPINALL, P.; MONTARZINO, A. The childhood factor: Adult visits to green places and the significance of childhood experience. Environment and Behavior, Online, v. 40, n. 1, p. 111-143, 2007.

TUAN, Y-F. Topofilia - Um estudo da percepção, atitudes e valores do meio ambiente. Londrina: EDUEL, 2012.

WHITE, A. Guidelines for field studies in environmental perception. Paris: Unesco 1977. 